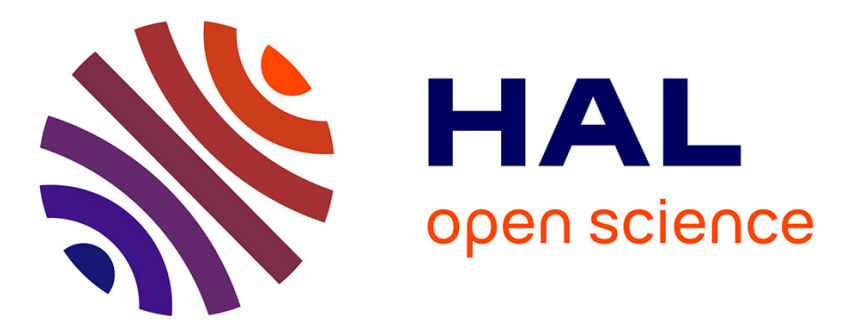

\title{
Effect of pressure and reinforcement type on the volume chemical shrinkage in thermoset resin and composite
}

\author{
Yasir Nawab, Nicolas Boyard, Frédéric Jaquemin
}

\section{To cite this version:}

Yasir Nawab, Nicolas Boyard, Frédéric Jaquemin. Effect of pressure and reinforcement type on the volume chemical shrinkage in thermoset resin and composite. Journal of Composite Materials, 2014, 48 (26), pp.3191-3199. 10.1177/0021998313502692 . hal-03286031

\section{HAL Id: hal-03286031 \\ https://hal.science/hal-03286031}

Submitted on 14 Jul 2021

HAL is a multi-disciplinary open access archive for the deposit and dissemination of scientific research documents, whether they are published or not. The documents may come from teaching and research institutions in France or abroad, or from public or private research centers.
L'archive ouverte pluridisciplinaire HAL, est destinée au dépôt et à la diffusion de documents scientifiques de niveau recherche, publiés ou non, émanant des établissements d'enseignement et de recherche français ou étrangers, des laboratoires publics ou privés. 


\title{
Effect of pressure and reinforcement type on the volume chemical shrinkage in thermoset resin and composite
}

\author{
Yasir Nawab', Nicolas Boyard ${ }^{2}$ and Frédéric Jaquemin ${ }^{3}$
}

\begin{abstract}
The diverse use of thermoset composite materials is increasing day by day in industrial applications. This has led to the development of several fabrication techniques, use of various reinforcement types, and different fabrication conditions to achieve a composite part with required properties. Despite all these technological advancements, there is a shear need to investigate and understand the effect of all these factors on the curing process. Volume chemical shrinkage of resin is one such property, which has been studied by several authors for a given value of applied pressure. A few studies have reported results on volume chemical shrinkage of composites for one type of reinforcement and for a single applied pressure. In the present work, experiments on vinylester resin and associated glass fibres composites were conducted under two different pressures. The tested composites were containing unidirectional fibres ([0] and [0/90]) and plain woven fabric with two different fibre volume fractions. The results of these experiments, carried out in a plunger type dilatometer, led us to show the effect of fibre fraction, type of reinforcement, and applied pressure on the volume chemical shrinkage of vinylester resin.
\end{abstract}

\section{Keywords}

Glass/vinylester composites, volume chemical shrinkage, dilatometry

\section{Introduction}

Chemical shrinkage of thermoset matrix is one of the major sources of cure-induced defects in composite parts for the aerospace, naval, and automotive applications. These defects include matrix cracking, fibre buckling, reduced strength, warping, and shape distortion. Characterization of chemical shrinkage is thus of crucial interest for modelling the residual stress ${ }^{1,2}$ and the resultant defects.

Several dilatometric techniques ${ }^{3-20}$ have been used for the characterization of chemical shrinkage. Out of these, plunger type dilatometer is mostly used for the determination of volume chemical shrinkage.

Plunger type instrument (also called PVT device) for thermoset resin can be compared to a syringe, which contains and pressurize the sample. The plunger of the syringe is monitored to follow the volume changes. Many authors ${ }^{6,7,21-26}$ used this instrument for the dilatometry on thermoset resins. This instrument in the beginning was only able to record volume changes under a low applied pressure. Later on, different improved versions of PVT device were developed, which worked under high pressure and also characterized several other resin properties.
This instrument has also been employed for the measurement of volume chemical shrinkage of composites. For example, Russell et al. ${ }^{27}$ used GNOMIX PVT device for the determination of global volume chemical shrinkage of UD-laminated (carbon/epoxy) composite. Same device was also used to study the epoxy moulding compound with and without fillers. ${ }^{28}$ Holst et al. ${ }^{29}$ determined the volume chemical shrinkage of epoxy system containing fillers using a laser scanning dilatometer.

PVT- $\alpha$ mould is a high pressure (up to $10 \mathrm{MPa}$ ) and high temperature (up to $200^{\circ} \mathrm{C}$ ) $\mathrm{PVT}$ device also

\footnotetext{
'Textile composite materials research group, faculty of engineering and technology, National Textile University, Sheikhupura road, Faisalabad, Pakistan

${ }^{2}$ Laboratoire Thermocinétique de Nantes, UMR 6607, Université de Nantes, La Chantrerie, rue Christian Pauc, Nantes, France

${ }^{3}$ Institut de Recherche en Génie Civil et Mécanique, Université de Nantes, 37 boulevard de l'Université, Saint-Nazaire, France
}

\section{Corresponding author:}

Yasir Nawab, Textile composite materials research group, faculty of engineering and technology, National Textile University, Sheikhupura road, 37610 Faisalabad - Pakistan.

Email: yasir.nawab@yahoo.com 
equipped with heat flux sensors. Therefore, it is able to measure simultaneously the flux density and hence the degree of cure, volume, and temperature of mould surface for a given hydrostatic pressure. ${ }^{30-32}$ In a recent work, results on the volume chemical shrinkage of vinylester resin and associated cross-ply composite under one pressure value have been reported considering the thermal gradients. ${ }^{32}$ The experimental data in that work were obtained from the tests using this device.

Parameters of fabrication of thermoset composites parts vary a lot according to nature of part and fabrication technique. Pressure applied during curing is one such parameter. In our knowledge, the effect of pressure on the volume chemical shrinkage of thermoset resin and composite is not reported yet. Moreover, the effect of reinforcement type on the volume chemical shrinkage of resin and composite is also rarely studied. Therefore, the objective of this work is to address these issues. In the present article, results on the volume chemical shrinkage of vinylester resin and associated glass composites under two pressure and heating ramp conditions are presented. For composites, the tests were conducted on unidirectional ([0], [0/90]) and fabric-reinforced composite samples having two different fibre fractions to study the effect of reinforcement type and the fibre fraction on their volume chemical shrinkage. The volume measurements of resin and composite during curing were taken using PVT- $\alpha$ mould. The contribution of thermal expansion to the total volume variation was calculated using thermal coefficients of sample and temperature profile. Chemical shrinkage was obtained by deducing thermal expansion from the experimental displacement curve.

\section{Materials and methods}

In this work, 14 types of resin and composites samples were tested. The list of these is given in Table 1. For each sample type, three repetitions were done. S1 and $\mathrm{S} 2$ were the pure vinylester resin samples tested under two different pressures $(\mathrm{P} 1=0.65 \mathrm{MPa}$ and $\mathrm{P} 2=0.32 \mathrm{MPa}$ ). This resin is available commercially with the name DERAKANE MOMENTUM 411-350 epoxy vinyl ester. Cobalt naphthenate $(0.05 \mathrm{wt} \%)$ was added as an initiator and $1 \mathrm{wt} \%$ catalyst NOROX MEKP-925H methylethylketone peroxide, MEKP) for initiating the chemical reaction.

Reinforcement types, stacking sequence, and pressure conditions for composite samples S3-S14 are given in Table 1. Both resin and composite samples were in the form of circular discs with diameter equal to $40.5 \pm 1 \mathrm{~mm}$ and thickness about $6 \mathrm{~mm}$. Density of unidirectional (UD) and woven fabric reinforcement was equal to $\left(300 \mathrm{~g} / \mathrm{m}^{2}\right)$. On PVT- $\alpha$ mould, sample
Table I. Different samples studied in this work.

\begin{tabular}{lllll}
\hline Sample & Reinforcement & $\begin{array}{l}\text { Stacking } \\
\text { sequence }\end{array}$ & Vf (vol\%) & Pressure \\
\hline SI & - & - & - & $\mathrm{PI}$ \\
S2 & - & - & - & $\mathrm{P} 2$ \\
S3 & Woven fabric & {$[0 / 90]$} & $32 \%$ & $\mathrm{PI}$ \\
S4 & Woven fabric & {$[0 / 90]$} & $32 \%$ & $\mathrm{P} 2$ \\
S5 & Woven fabric & {$[0 / 90]$} & $49 \%$ & $\mathrm{PI}$ \\
S6 & Woven fabric & {$[0 / 90]$} & $49 \%$ & $\mathrm{P} 2$ \\
S7 & UD & {$[0 / 90]$} & $32 \%$ & $\mathrm{PI}$ \\
S8 & UD & {$[0 / 90]$} & $32 \%$ & $\mathrm{P} 2$ \\
S9 & UD & {$[0 / 90]$} & $49 \%$ & $\mathrm{PI}$ \\
S10 & UD & {$[0 / 90]$} & $49 \%$ & $\mathrm{P} 2$ \\
S1I & UD & {$[0]$} & $32 \%$ & $\mathrm{PI}$ \\
S12 & UD & {$[0]$} & $32 \%$ & $\mathrm{P} 2$ \\
SI3 & UD & {$[0]$} & $49 \%$ & $\mathrm{PI}$ \\
SI4 & UD & {$[0]$} & $49 \%$ & $\mathrm{P} 2$ \\
\hline
\end{tabular}

weight varies between 8 and $16 \mathrm{~g}$ depending on the fibre volume fraction.

Samples were cured using following thermal cycle: maintaining at room temperature for $2 \mathrm{~min}$, heating to $180^{\circ} \mathrm{C}$ at the rate of $4^{\circ} \mathrm{C} / \mathrm{min}$, maintaining at $180^{\circ} \mathrm{C}$ for $10 \mathrm{~min}$, and finally cooling to room temperature at $4^{\circ} \mathrm{C} / \mathrm{min}$. Since glass transition temperature of the resin is about $118^{\circ} \mathrm{C}$, heating above this temperature was done to ensure complete curing of samples.

Experiments were also conducted on resin samples using Differential Scanning Calorimeter DSC (TA Q200 from TA Instruments ${ }^{\circledR}$ ) to determine the heat of cure of resin samples. Five samples of about $10 \mathrm{mg}$ of resin were tested using the curing cycle presented above. Heat of cure was found by integrating the heat flux density peak using a sigmoid base line. Glass transition temperature of the cured resin was also determined using this instrument.

Like other PVT devices, PVT- $\alpha$ mould (Figure 1) consists of a piston, which is able to move in a cylindrical stainless steel cavity having a 61-mm internal diameter. The heat transfer is one dimensional and along the sample thickness. Heaters installed at the bottom of mould cavity and in the piston ensure uniform heating of sample surfaces. Heat flux sensors ${ }^{33}$ placed each in the bottom of cavity and in the piston record the heat flux. The mould is placed between two platens of an electric press. Servo motors adjust the position of the piston is the real time to keep the pressure constant. More details about this device are given in Boyard et al. ${ }^{34}$ and Millischer. ${ }^{35}$

Silicon pouch (Figure 1) is available in two portions: a small container and a lid. Before placing in the mould cavity, reinforcement (if any) is placed in the container 


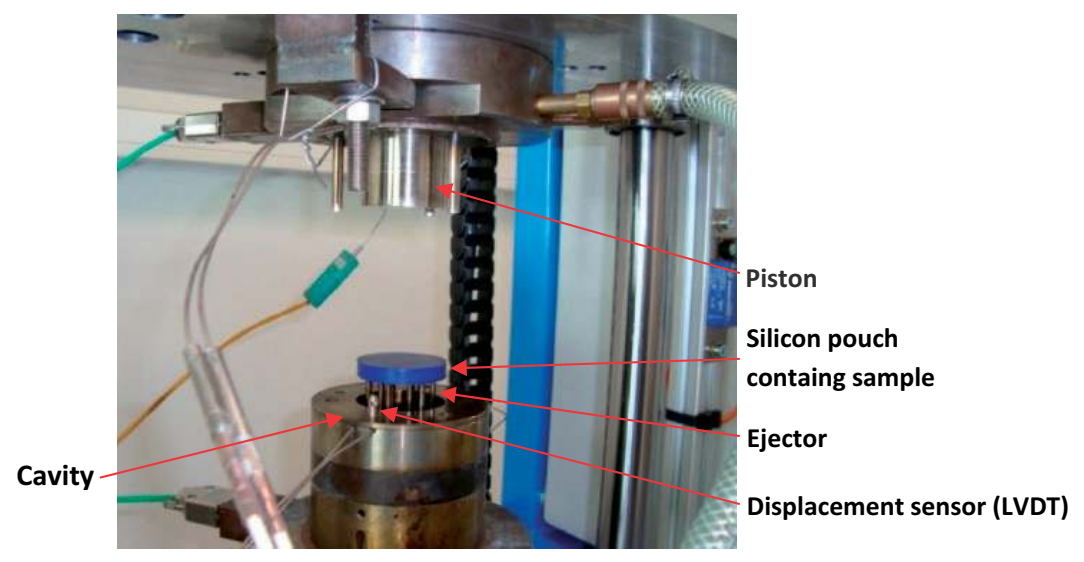

Figure I. A snapshot of PVT- $\alpha$ showing moulding cavity, piston and silicon pouch containing sample.

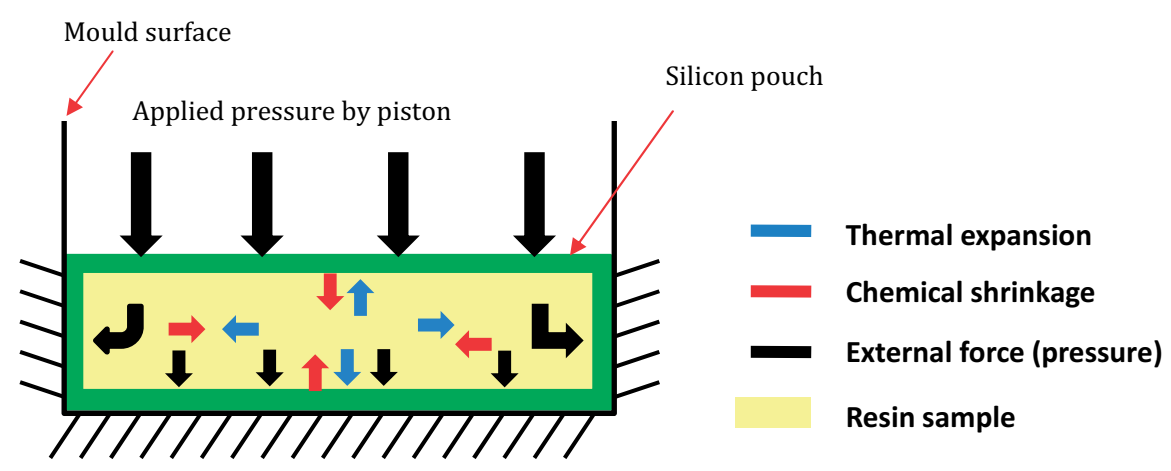

Figure 2. Schematic representation of the sample volume variations induced by phenomena occurring during the PVT- $\alpha$ experiment in a silicon capsule.

and sealed with the lid using the silicon adhesive. The resin is then injected in the pouch using vacuum assistance. This also helps to remove air bubbles. Once the pouch containing resin or composite is placed in mould cavity and test is launched, the piston moves following the variations of the sample volume to maintain a constant hydrostatic pressure. These variations are recorded by linear variable differential transformer (LVDT) displacement sensor with a precision of $1 \mu \mathrm{m}$ and a limit of $10 \mathrm{~mm}$.

A schematic representation of volume variations of the sample in the silicon pouch during curing and external pressure applied by piston during the PVT- $\alpha$ experiment are given in Figure 2. Thermal expansion/ contraction due to heating/cooling and/or exothermic reaction and chemical shrinkage due to crosslinking causes the changes in volume. Since the surface of the silicon pouch, on which the constant pressure is applied, does not vary, the change in volume appears as a change in thickness and recorded by LVDT sensor.

\section{Results and discussions}

\section{Interpretation of heat flux density and thickness variation curves}

Resin and composite samples were cured according to thermal cycle and pressure conditions presented in Materials and methods section. A reference experiment was run on an aluminium disc with known properties enclosed in a silicon pouch. The objective was to determine the possible heat loss to the mould and thermal expansion of the LVDT sensor, silicon pouch, and the mould. Temperature cycle described in precedent section was used under two pressure conditions. The results of these experiments were used later as base lines for displacement and heat flux density while treating the data.

After data treatments and subtraction of respective base lines, the total heat flux density $(\varphi)$ and the thickness variation purely associated to the resin or composite were obtained. 


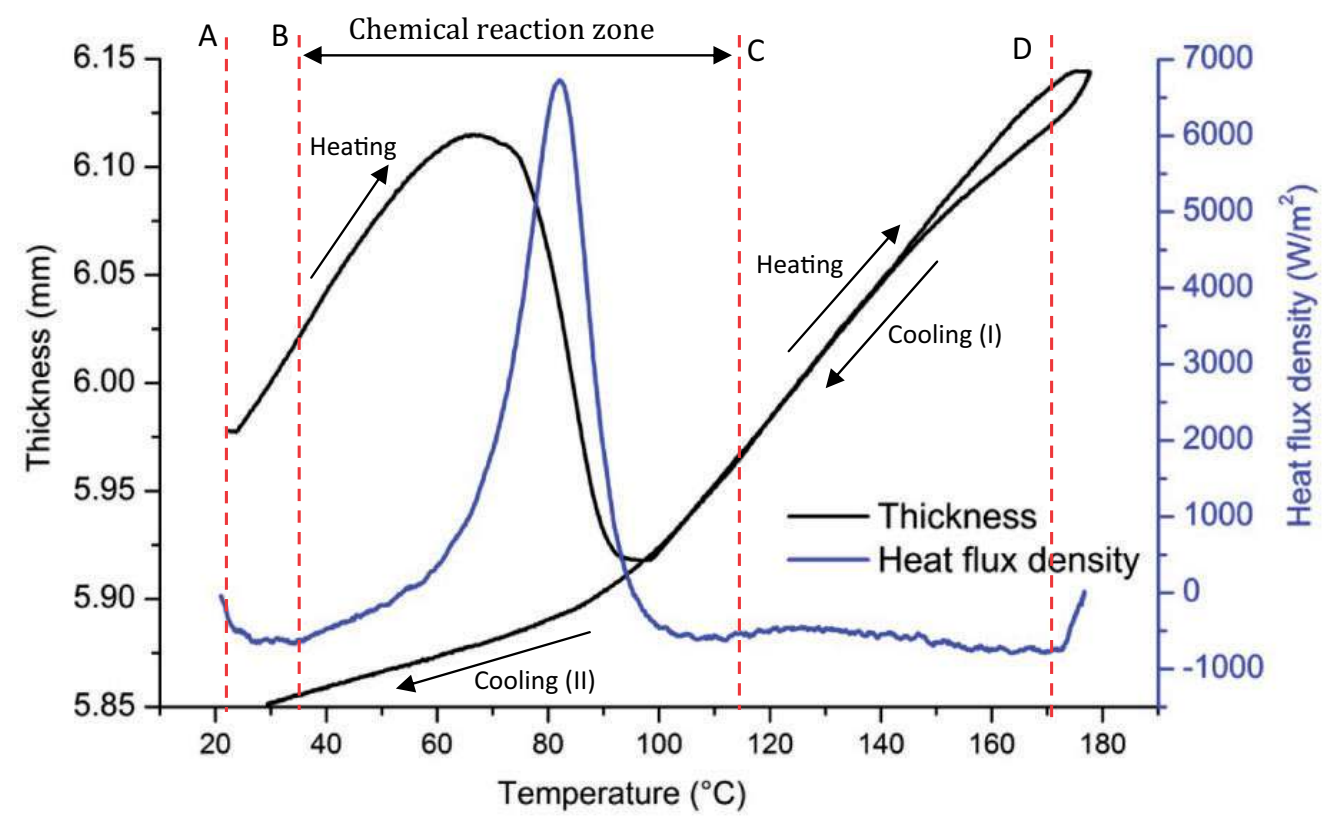

Figure 3. Thickness variation of neat resin sample during the curing and cooling versus temperature, heat flux density during curing is also plotted.

An example of thickness variation of the resin sample (S1) during the thermal cycle, and the associated heat flux data (for heating step only) versus surface temperature of sample are presented in Figure 3. As described earlier, the thickness variation corresponds to volume change. During the heating cycle, this thickness variation was the result of thermal expansion and chemical shrinkage while the only prominent phenomenon during cooling cycle was the thermal contraction.

Linear part (zone A-B) of the thickness curve represents the thermal expansion of neat resin. The slope of thickness curve in this zone gave the volume coefficient of thermal expansion $\left(\mathrm{CTE}_{\text {uncured }}\right)$ of neat resin. As the reaction starts at low temperature, this region is very small. Since the reaction was not started in this zone, an endothermal effect was observed on heat flux curve due to the heating of the sample.

Exothermic heat flux in a thermoset resin due to crosslinking of molecules gives an idea about chemical reaction in the resin. It can be noted from heat flux density curve that the chemical reaction started from B (exothermy started at the same temperature) and completed or became very slow on reaching C. Since temperature was also increasing, the shrinkage was coupled with thermal expansion. Because of beginning of chemical reaction, a little deviation from linear behaviour of thickness curve at B was observed. But later, the thickness curve took a $U$ turn due to high chemical shrinkage. The chemical reaction was at its peak (heat flux density curve) at this time. In the zone $\mathrm{C}-\mathrm{D}$, the prominent effect was again thermal expansion and the curve is quasi linear. Since glass transition occurred near $\mathrm{C}$, the resin was in rubbery solid state in zone $\mathrm{C}-\mathrm{D}$. The coefficient of solid rubbery resin $\left(\mathrm{CTE}_{\text {rubbery }}\right)$ was found by calculating the slope of thickness curve in zone $\mathrm{C}-\mathrm{D}$.

During the cooling step (in zone $\mathrm{C}-\mathrm{D}$ ), a hysteresis of thickness curve was observed in the beginning, but later both the cooling and heating thickness curves superimposed. During cooling, thickness curve can be divided into two portions with two different slopes (I and II). This difference is due to change of material state from rubbery to glassy state.

The difference between initial thickness (at the start of heating) and final thickness at the end of cooling is equal to the apparent shrinkage of material which was found equal to $2.1 \pm 0.4 \mathrm{vol} \%$ for neat vinylester resin. It should be noted that apparent shrinkage is always lesser than chemical shrinkage. This is because of the fact that thermal expansion coefficients of uncured or partially cured resin in liquid or gelled state during heating are much higher than thermal expansion coefficient of solid cured resin during cooling. Due to this difference, one cannot observe the whole effect of chemical shrinkage.

In order to determine chemical shrinkage, the first step was to calculate thermal expansion of sample in zone B-C. Determination of coefficients of thermal expansion was required for this purpose. Since the 


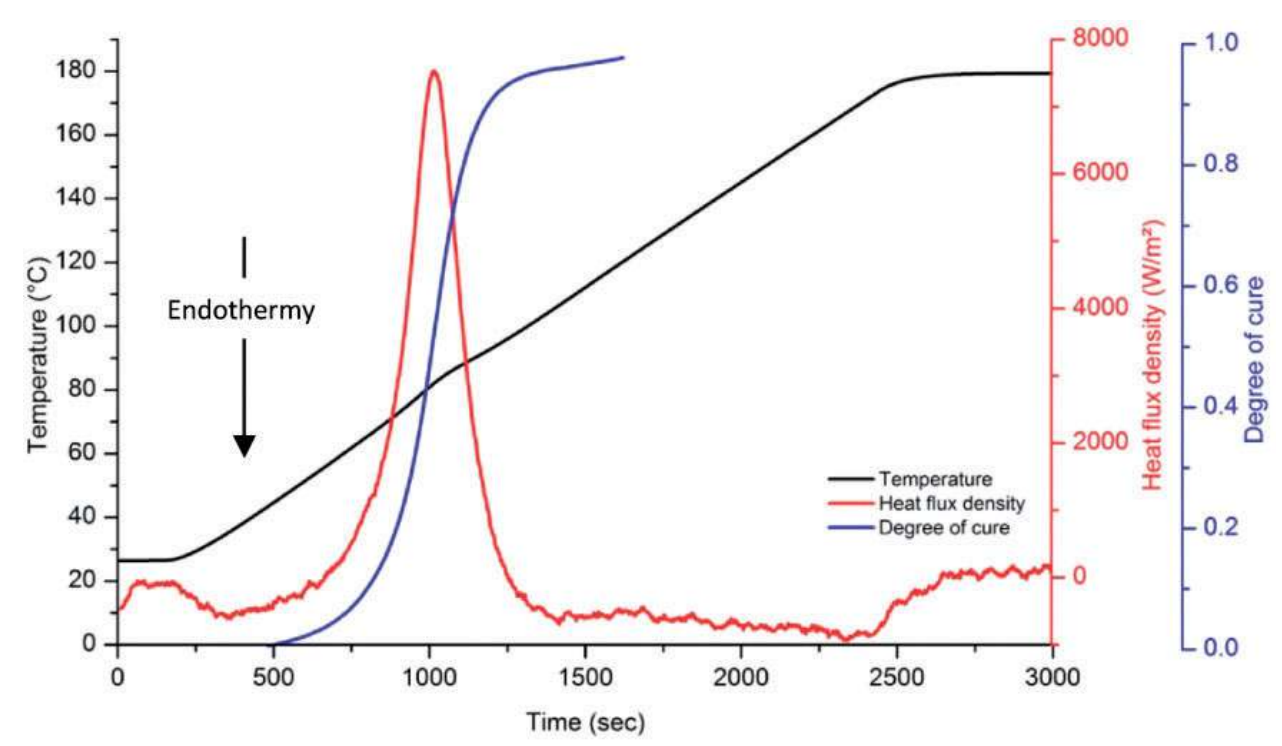

Figure 4. Heat Flux curves recorded during curing of neat resin, calculated degree of cure is also plotted versus time.

evolution of properties of resin from uncured to cured state depends on degree of cure $(\alpha)$, mixing law (1) was used to find coefficient of thermal expansion $\operatorname{CTE}(\alpha)$ for a give value of degree of cure $\alpha$ in the curing zone $\mathrm{B}-\mathrm{C}$.

$$
\operatorname{CTE}(\alpha)=\operatorname{CTE}_{\text {uncured }}(1-\alpha)+\alpha \operatorname{CTE}_{\text {curedrubbery }}
$$

Total heat of cure was determined by integrating the heat flux curve using sigmoid base line. The average value for three resin sample was found equal to $\Delta \mathrm{H}_{\mathrm{avg}}=325 \pm 4.2 \mathrm{~J} / \mathrm{g}$. From the DSC experiments, average value of total heat of cure of five samples was found equal to $324.9 \pm 3.6 \mathrm{~J} / \mathrm{g}$. This shows that the results of both instruments are in agreement. Using DSC, the glass transition temperature of fully cured resin was found equal to $118 \pm 0.9^{\circ} \mathrm{C}$ versus the manufacturer provided value of $120^{\circ} \mathrm{C}$.

If it is considered that temperature through the thickness of sample is uniform, then degree of cure will also be uniform in the sample. Its value at time instant ( $\mathrm{t}$ ) can be determine by integrating the heat flux curve until that time and dividing by total heat of cure:

$$
\alpha(t)=\int_{0}^{t} \frac{\varphi d t}{\Delta H_{t o t}}
$$

Here $\alpha(t)$ is the degree of cure at a given time instant, $\Delta H_{t o t}$ is the total heat of reaction released, and $\varphi$ is the heat flux density. Temperature profile during the heating of a resin sample, heat flux density, and degree of cure $(\alpha)$ calculated using equation (2) is plotted in Figure 4 versus time in seconds.
Figure 5 shows an example of thickness variation and heat flux density versus temperature graph of cross-ply glass/vinylester composite sample having 16 plies $\left(\mathrm{V}_{\mathrm{f}}=32 \%\right)$. Evolution of both curves is similar to that of resin presented in Figure 3. The heat flux curve started from zero followed by an endothermy. The reaction in case of composite was a little delayed as compared to resin and can be attributed to the difference of sample preparation time. The heat flux density returned to zero during the isothermal step at $180^{\circ} \mathrm{C}$. Thickness curves of composite during the cooling step did not superimpose.

This might be due to the limitation of hypothesis made that elastomer acted like a fluid and was fully able to compensate the volume changes caused by shrinkage or expansion. In our view, this hypothesis is applicable to resin/composite in liquid, gel, and/or in rubbery state, because in this state, liquid, or gelled resin allowed the elastomer to flow thanks to the applied pressure. But once the resin is glassy, it is not possible for elastomer to fill all the vacant spaces created by thermal contraction.

\section{Determination of chemical shrinkage}

Determination of chemical shrinkage is a complex phenomenon due to its strong coupling with thermal expansion/shrinkage. If thermal gradients are present, finding the solution becomes more difficult due to the existence of gradients of thermophysical properties and degree of cure through the sample. It has already been shown in the literature ${ }^{32}$ that presence of thermal gradient effects only the evolution of chemical shrinkage of resin versus degree of cure. Otherwise, total chemical shrinkage remains unaffected. In case of composite, the 


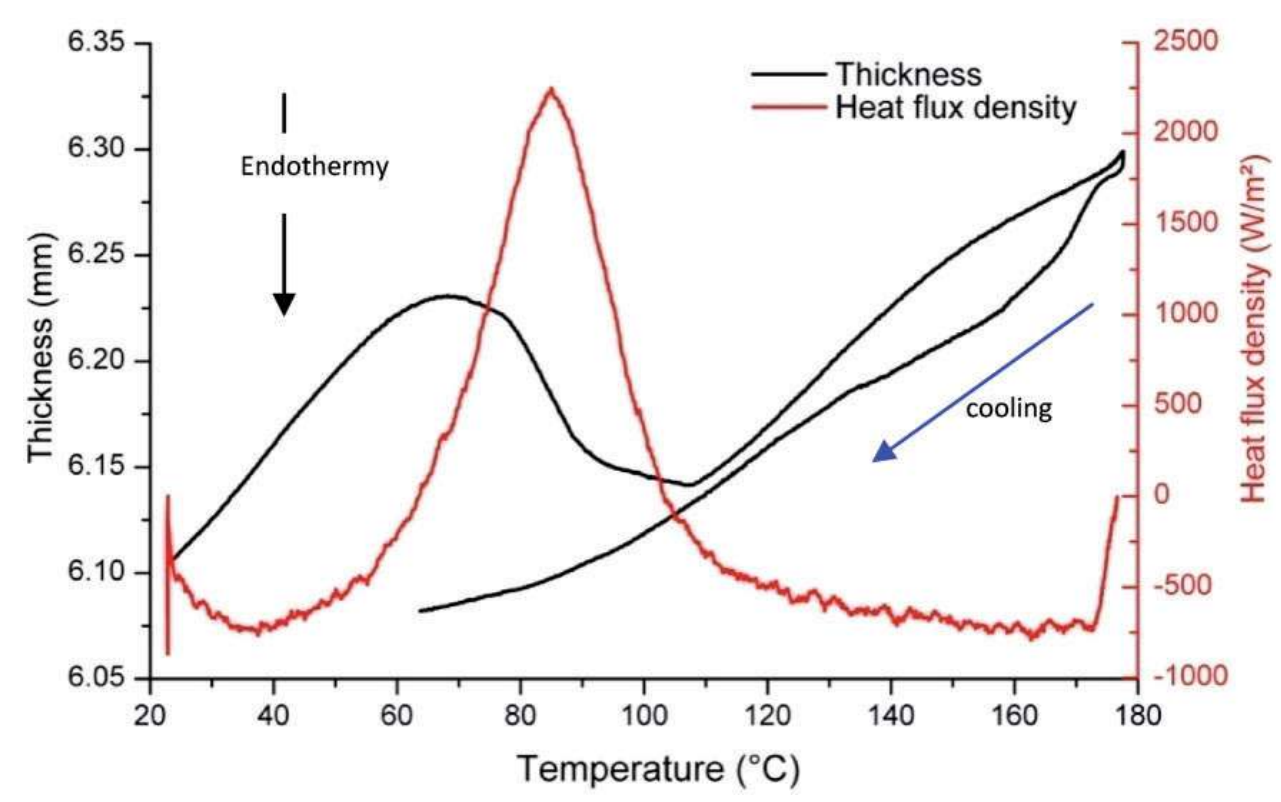

Figure 5. Variation of thickness of and associated heat flux density (during heating step only) of glass/vinylester cross-ply composite sample (32 vol\%).

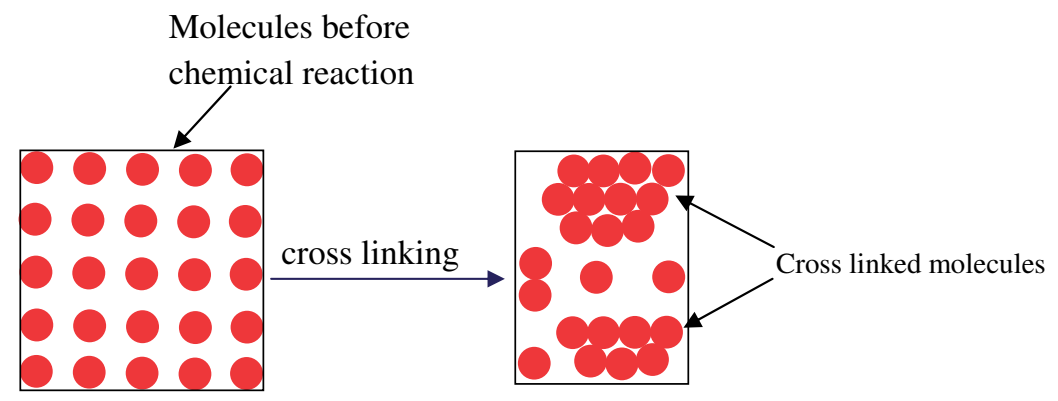

Figure 6. Illustration of increasing molecular network size and shrinkage with crosslinking.

effect of thermal gradients on both evolution and total chemical shrinkage is not significant, which is because of the low amount of resin present in them. Therefore, it was decided to neglect the effect of thermal gradients for the simplicity of calculations. With this assumption, it is simple to determine chemical shrinkage $\left(d_{i} C S \Delta \alpha\right)$ using equation (3)

$$
d_{i} C S \Delta \alpha=d(T, \alpha)-d_{i}(1+C T E(\alpha) \Delta T)
$$

where $d_{i}$ is the initial thickness of the sample. CS is the coefficient of chemical shrinkage, which is defined as $C S=\frac{\Delta d_{\text {shrinkage }}}{d_{i} \Delta \alpha}$. It has no units. $C T E(\alpha)$ is the coefficient of thermal expansion of sample calculated using equation (1).

Effect of fibre fraction. As illustrated in Figure 6, molecules of liquid matrix move freely. With the beginning of the chemical reaction, networks of molecules are formed. After passing the gel point of the matrix, the size of these molecular networks is increased so much that their mobility is reduced. In the presence of reinforcement, an adhesion of these molecules is also created with the fibres. The fibre-matrix adhesion and the physical blockage by fibres, in addition to bulk of molecules, hinder the molecular movement (due to chemical shrinkage or thermal expansion) from this point. This resulted into the formation of micro residual stresses among fibres and matrix. The hindrance by fibres increases with the proceeds of chemical reaction due to the formation of bigger molecular networks.

To study the effect of presence of fibres on the chemical shrinkage, shrinkage of each composite sample was converted to shrinkage of an equivalent mass of neat resin. The results for resin (S1) and UD composites with [0/90] stacking sequence under P1 pressure (samples S7 and S10) are shown in Figure 7. It can be noted that shrinkage of resin without fibres is higher than the 


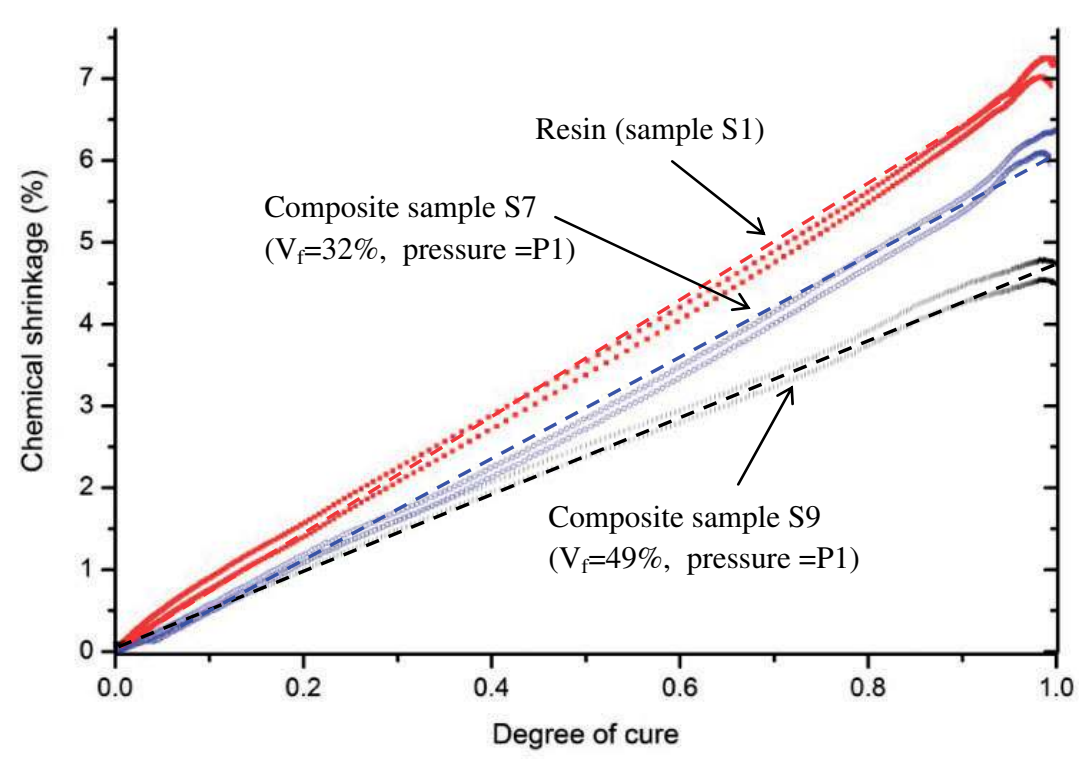

Figure 7. Chemical shrinkage of resin and equivalent composite [0/90] shrinkage versus degree of cure.

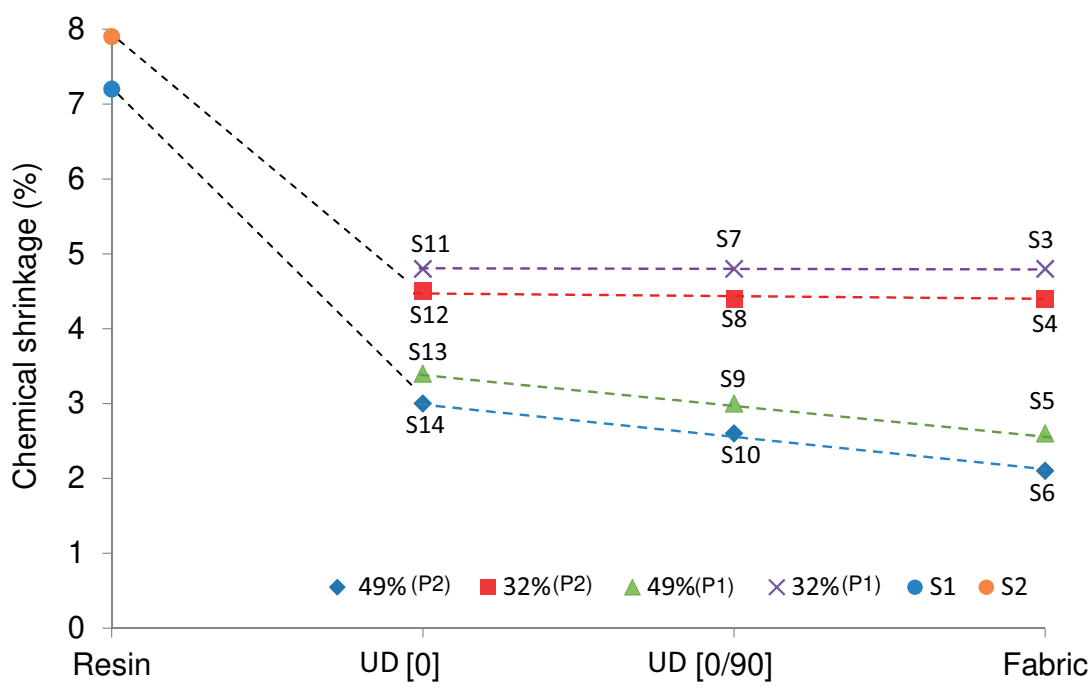

Figure 8. Volume chemical shrinkage of resin and various composite samples.

shrinkage of the same quantity of resin with the fibres. It means the presence of fibres hinders the resin to shrink chemically during curing. The difference increases by increasing the fibre fraction. Similar results were found for other reinforcement types.

Effect of reinforcement type. In addition to unidirectional fibres, woven reinforcement is becoming more and more popular in the industrial applications due to the defined distribution of fibres ${ }^{36}$ and rigid structure. In general, liquid composite moulding is used for such type of composite fabrication. The results of volume chemical shrinkage of resin, UD composites ([0] and $[0 / 90]$ ), and plain woven fabric-reinforced composites under two pressure conditions are presented in Figure 8 . The evolution of chemical shrinkage versus degree of cure was found linear but for a better understanding only the final values of shrinkage are plotted in this figure. All the samples names are also written on each experimental value of shrinkage. Dashed lines are added only to show the shrinkage trend.

For a given value of pressure and fibre volume fraction, we were expecting that due to the stiffness of the structure, chemical shrinkage of fabric composite $<$ chemical shrinkage of $[0 / 90]$ composite $<$ chemical shrinkage [0] composite. But for $32 \%$ fibre volume fraction, the results show that there is no significant effect of type of reinforcement type on the 
chemical shrinkage. In fact for such low volume fraction, the hindrance of the fibres is weak. However, a prominent effect can be noted in case of higher fibre volume fraction $(49 \%)$ as shown in Figure 8.

Effect of pressure. Application of pressure is necessary to avoid air bubbles and for consolidation of composite part during fabrication. The amount of applied pressure depends on various parameters including matrix type, fabrication technique, and type of composite. The free volume decreases and chemical shrinkage increases due to the applied pressure on resin during its curing. Any change in chemical shrinkage may lead to the change in induced residual stress and hence shape distortion of the part. Therefore, it is essential to study the effect of applied pressure on the chemical shrinkage of matrix and composites. It has been shown by Nawab et al. ${ }^{32}$ that the application of pressure over a short period of time does not affect the amount of heat released during curing and has not changed chemical shrinkage significantly.

In the present study, resin and composites were cured under two different pressures (hydrostatic), which were maintained throughout the curing process. It can be noted that for all reinforcement types and fibre volume fraction, the effect of pressure on chemical shrinkage is significant. The value of shrinkage at higher pressure (P1) is higher than the value of shrinkage at low pressure (P2).

\section{Conclusion}

In this study, volume chemical shrinkage of vinylester resin and associated glass fibre composites containing UD fibres and plain woven fabric as reinforcement is studied. Experiments on composite samples were done with two fibre volume fractions. All the tests were conducted under two pressures. The results of experiments showed that pressure applied during the curing of matrix affects significantly the volume chemical shrinkage of resin and composite. Keeping all other factors constant, volume chemical shrinkage increases by increasing the pressure. Moreover, the presence of fibres in matrix hinders its chemical shrinkage. For a given reinforcement, shrinkage blockage of sample having a greater fibre volume fraction is higher in comparison with composite containing low fibre volume fractions. It was also observed that for a given fibre volume fraction, volume chemical shrinkage of fabric $<$ shrinkage of [0/90] composite $<$ shrinkage of [0] composite. This leads to the conclusion that for the given values of fibre volume fraction and pressure applied, the volume chemical shrinkage will be lesser for the stiffer reinforcements.

\section{Funding}

The experimental work was supported by the Laboratoire de Thermocinétique de Nantes (LTN), Université de Nantes, France.

\section{Conflict of interest}

None declared.

\section{References}

1. Shimbo M, Yamabe M and Miyano Y. Viscoelastic analysis of residual stress in thermosetting resins introduced during curing process. In: 11th international conference on experimental mechanics. 1998, pp.1325-1330.

2. Nawab Y, Jacquemin F, Casari P, et al. Evolution of chemical and thermal curvatures in thermoset laminated composite plates during the fabrication process. J Compos Mater 2013; 47: 327-339.

3. Snow AW and Armistead JP. A simple dilatometer for thermoset cure shrinkage and thermal expansion measurements. J Appl Polym Sci 1994; 52: 401-411.

4. Yan-Jyi H and Chiou-Ming L. Volume shrinkage characteristics in the cure of low-shrink unsaturated polyester resins. Polymer 1996; 37: 401-412.

5. Kinkelaar M and Lee LJ. Development of a dilatometer and its application to low-shrink unsaturated polyester resins. J Appl Polym Sci 1992; 45: 37-50.

6. Kinkelaar M, Muzumdar S and Lee LJ. Dilatometric study of low profile unsaturated polyester resins. Polym Eng Sci 1995; 35: 823-836.

7. Madhukar MS, Genidy MS and Russell JD. A new method to reduce cure-induced stresses in thermoset polymer composites, part I: test method. $J$ Compos Mater 2000; 34: 1882-1904.

8. Li C, Potter K, Wisnom MR, et al. In-situ measurement of chemical shrinkage of MY750 epoxy resin by a novel gravimetric method. Compos Sci Technol 2004; 64: 55-64.

9. Parlevliet PP, Bersee HEN and Beukers A. Shrinkage determination of a reactive polymer with volumetric dilatometry. Polym Test 2010; 29: 433-439.

10. Shah DU and Schubel PJ. Evaluation of cure shrinkage measurement techniques for thermosetting resins. Polym Test 29: 629-639.

11. Schoch KF, Panackal PA and Frank PP. Real-time measurement of resin shrinkage during cure. Thermochim Acta 2004; 417: 115-118.

12. Parlevliet PP, Bersee HEN and Beukers A. Measurement of (post-)curing strain development with fibre Bragg gratings. Polym Test 2010; 29: 291-301.

13. Antonucci V, Giordano M, Cusano A, et al. Real time monitoring of cure and gelification of a thermoset matrix. Compos Sci Technol 2006; 66: 3273-3280.

14. Karalekas D, Cugnoni J and Botsis J. Monitoring of process induced strains in a single fibre composite using FBG sensor: a methodological study. Compos A Appl Sci Manuf 2008; 39: 1118-1127.

15. Giordano M, Laudati A, Nasser J, et al. Monitoring by a single fiber Bragg grating of the process induced 
chemo-physical transformations of a model thermoset. Sens Actuators Phys 2004; 113: 166-173.

16. Vacher S, Molimard J, Gagnaire H, et al. A fresnel's reflection optical fiber sensor for thermoset polymer cure monitoring. Polym Polym Compos 2003; 12: 269-276.

17. Tai HJ and Chou HL. Chemical shrinkage and diffusioncontrolled reaction of an epoxy molding compound. Eur Polym J 2000; 36: 2213-2219.

18. Lange $\mathrm{J}$, Toll S, Månson $\mathrm{J}$-AE, et al. Residual stress build-up in thermoset films cured above their ultimate glass transition temperature. Polymer 1995; 36 : 3135-3141.

19. Yang DG, Jansen KMB, Ernst LJ, et al. Effect of filler concentration of rubbery shear and bulk modulus of molding compounds. Microelectr Reliab 2007; 47: 233-239.

20. Hoa SV, Ouellette P and Ngo TD. Determination of shrinkage and modulus development of thermosetting resins. J Compos Mater 2009; 43: 783-803.

21. Russell JD, Madhukar MS, Genidy MS, et al. A new method to reduce cure-induced stresses in thermoset polymer composites, part III: correlating stress history to viscosity, degree of cure, and cure shrinkage. J Compos Mater 2000; 34: 1926-1947.

22. Zoller P, Bolli P, Pahud V, et al. Apparatus for measuring pressure-volume-temperature relationships of polymers to $350^{\circ} \mathrm{C}$ and $2200 \mathrm{~kg} / \mathrm{cm}^{2}$. Rev Sci Instrum 1976; 47: 948

23. Li W and Lee LJ. Low temperature cure of unsaturated polyester resins with thermoplastic additives: I. Dilatometry and morphology study. Polymer 2000; 41: 685-696.

24. Ramos JA, Pagani N, Riccardi CC, et al. Cure kinetics and shrinkage model for epoxy-amine systems. Polymer 2005; 46: 3323-3328.

25. Hwang S-J and Chang Y-S. Isobaric cure shrinkage behaviors of epoxy molding compound in isothermal state. J Polym Sci B Polym Phys 2005; 43: 2392-2398.
26. Li W and Lee LJ. Shrinkage control of low-profile unsaturated polyester resins cured at low temperature. Polymer 1998; 39: 5677-5687.

27. Russell JD. Cure shrinkage of thermoset composites. SAMPE Q 1993; 24: 28-33.

28. Sadeghinia M, Jansen KMB and Ernst LJ. Characterization and modeling the thermo-mechanical cure-dependent properties of epoxy molding compound. Int $J$ Adhes Adhes 2012; 32: 82-88.

29. Holst M, Schänzlin K, Wenzel M, et al. Time-resolved method for the measurement of volume changes during polymerization. J Polym Sci B Polym Phys 2005; 43: 2314-2325.

30. Nawab Y, Boyard N, Sobotka V, et al. Measurement and modelling of chemical shrinkage of thermoset composites. Key Eng Mater 2012; 504: 1129-1134.

31. Nawab Y, Boyard N, Sobotka V, et al. A device to measure the shrinkage and heat transfers during the curing cycle of thermoset composites. Adv Mater Res 2011; 326: 19-28.

32. Nawab Y, Tardif X, Boyard N, et al. Determination and modelling of the cure shrinkage of epoxy vinylester resin and associated composites by considering thermal gradients. Compos Sci Technol 2012; 73: 81-87.

33. Massé H, Arquis É, Delaunay D, et al. Heat transfer with mechanically driven thermal contact resistance at the polymer-mold interface in injection molding of polymers. Int J Heat Mass Transf 2004; 47: 2015-2027.

34. Boyard N, Vayer M, Sinturel C, et al. Modeling PVTX diagrams: application to various blends based on unsaturated polyester - influence of thermoplastic additive, fillers, and reinforcements. J Appl Polym Sci 2004; 92: 2976-2988.

35. Millischer A. Transferts thermiques dans le procede d'injection BMC (Bulk Molding Compound). $\mathrm{PhD}$ Thesis, Université de Nantes, 2000.

36. Nawab Y, Legrand X and Koncar V. Study of changes in 3D-woven multilayer interlock fabric preforms while forming. J Text Inst 2012; 103: 1273-1279. 